\title{
Deep Spatial Discrimination in the Lumbar Spine
}

\author{
Bo Nystrom ${ }^{1}$, Adam Taube ${ }^{2}$, Eliza Leja ${ }^{2}$ and Birgitta Schillberg ${ }^{1}$ \\ ${ }^{1}$ Clinic of Spinal Surgery, Lot, SE-64594 Strangnas, Sweden \\ ${ }^{2}$ Department of Statistics, Uppsala University, SE-75120 Uppsala, Sweden
}

Corresponding author: Bo Nystrom, Clinic of Spinal Surgery, Lot, SE-64594 Strangnas, Sweden, Present Address: Regementsgatan 20 B, SE-64533 Strangnas, Sweden, Tel: +46 70 3724962, E-mail: pgbo.nystrom@gmail.com

Received: Oct 13, 2016; Accepted: Nov 28, 2016; Published: Nov 30, 2016

Citation: Nystrom B, Taube A, Leja E, et al. Deep Spatial Discrimination in the Lumbar Spine. J Neurol Neurosci. 2016, 7:6.

\section{Abstract}

Background: In patients with chronic low back pain (CLBP) who undergo fusion surgery, selecting the level to fuse has been based on radiological findings, the pain reaction at discography, disc-block and temporal external fixation, tests all found to be unreliable. An alternative would be to rely on spatial discrimination. Our objective was therefore to test if healthy volunteers are able to discriminate between lumbar vertebrae bordering one another (adjacent) and those that are one or two vertebrae apart (separated).

Methods and findings: Eighteen volunteers participated in the study. Short injection needles were introduced into the top of the spinous processes of the L3, L4, L5 and S1 vertebrae. One vertebra was tapped in the pair being tested and immediately thereafter the other vertebra was tapped. The subject then had to decide whether the two tapped vertebrae were adjacent to one another or separated. Outcome was measured as the number of correctly specified pairs, out of the 12 alternatives, obtained for each test subject.

Results: For all 18 volunteers there were altogether 87 correct classifications among the adjacent pairs of vertebrae giving a mean of $0.805,99 \% \mathrm{Cl}(0.69 ; 0.89)$ bootstrap. This was regarded as the sensitivity. In the same manner the number of 96 correctly classified separate pairs gives a specificity of $0.89,99 \% \mathrm{Cl}(0.70$; $0.95)$ bootstrap.

Conclusion: We found our test useful in discriminating deep structures of the spine lying only $2-3 \mathrm{~cm}$ apart. It might therefore be useful when searching for a possibly painful segment in patients with CLBP.

Keywords: Chronic low back pain; Deep lumbar structures; Experimental study; Fusion surgery; Painful segment; Spatial discrimination; Volunteers

\section{Introduction}

Spatial discrimination in the skin has been found to be rather crude in the lumbar area when tested by two-pointdiscrimination (TPD) in normal subjects [1] and to be even poorer in chronic back pain patients than in normal volunteers $[2,3]$. To our knowledge there is no report concerning spatial discrimination in deeper structures of the lumbar spine.

In patients suffering from chronic low back pain (CLBP) one of the major problems is to localize the possibly painful segment or disc when intending to treat the patient by fusion operation. Various methods have been used for this purpose but at present there is no reliable test to pinpoint a painful disc $[4,5]$, if present. An alternative could perhaps be mechanical testing relying on deep spatial discrimination, provided such discrimination in the lumbar spine would be sufficiently precise. Our aim was therefore to test the ability of healthy volunteers without back pain to discriminate between vertebrae bordering one another (adjacent) and those lying one or two vertebrae apart (separated).

\section{Methods}

Eighteen volunteers participated in the study, 8 men and 10 women, mean age 46 years (range $25-63$ years). All subjects were thoroughly informed about the procedure, verbally and in writing, and gave their written informed consent. The study was approved by the Central Ethics Committee, Stockholm, Ö 50-2012.

\section{Technical procedure}

The test subject lies prone on an X-ray table. Under X-ray control short 18 gauge $(1.2 \mathrm{~mm})$ injection needles are introduced perpendicular to the skin into the top of the spinous processes of the L3, L4, L5 and S1 vertebrae, denoted as $A, B, C$ and $D$ during testing. When in contact with the process they are tapped slightly into the bone, thereby remaining in a fixed position. A small amount of Lidocaine, usually $0.1 \mathrm{ml}$, is injected in order to anaesthetize the periosteum around the needle tip. In that way slight tapping of the needles is felt only as tapping inside the spine, and not as pain. 
One vertebra in the pair being tested is tapped, and thereafter the other vertebra is immediately tapped, after which the subject has to decide whether the two tapped vertebrae are adjacent (adj.) to one another or separated (sep.). When using all alternatives comprising the four vertebrae in question, 16 pairs emerge. However, in four of these pairs the same vertebra is being tapped twice, $A A, B B$ etc., and these were not used in the test situation. The remaining 12 pairs, six adjacent vertebrae and six separated vertebrae, are those analysed (Table 1). The 12 pairs are tested in a random order specific for each subject, and neither the subject nor the surgeon performing the testing knows in advance which pair is to be tested. The surgeon is informed about the pair to be tested by a co-worker holding up a poster, e.g. $A D, C B$, etc., that is not seen by the subject.

Table 1 Scheme showing the testing alternatives, adjacent and separated, when tapping pairs of vertebrae.

\begin{tabular}{|l|l|l|l|l|}
\hline \multicolumn{2}{|l|}{ Testing scheme } \\
\hline $\begin{array}{l}\text { Second } \\
\text { vertebra } \\
\text { tapped }\end{array}$ & \multicolumn{4}{|l|}{ First vertebra tapped } \\
\hline & A & B & C & D \\
\hline A & --- & adj. & sep. & sep. \\
\hline B & adj. & --- & adj. & sep. \\
\hline C & sep. & adj. & --- & adj. \\
\hline D & sep. & sep. & adj. & --- \\
\hline
\end{tabular}

Thus, data with the structure shown in Table $\mathbf{2}$ were obtained for each subject. The numbers of correct classifications of adjacent and of separated vertebrae pairs are denoted by $\mathrm{Xa}$ and $\mathrm{Xs}$, respectively, and their sum, Xa + Xs, i.e., the total number of correct classifications, is denoted by $X$.

Table 2 Number of correctly specified adjacent and separated vertebrae pairs, Xa and Xs, respectively, for each subject.

\begin{tabular}{|l|l|l|}
\hline \multicolumn{2}{|l|}{ Classification of tested pairs of vertebrae } \\
\hline $\begin{array}{l}\text { Subject } \\
\text { Classification }\end{array}$ & True status \\
\cline { 2 - 3 } & Adjacent & Separated \\
\hline Adjacent & Xa & $6-X s$ \\
\hline Separated & $6-X a$ & $X s$ \\
\hline
\end{tabular}

Before the actual testing of the 12 pairs, each volunteer was introduced to the testing procedure and the possibility of recognizing adjacent and separated pairs of vertebrae by a round of training. During this training the surgeon tapped all the 12 combinations in random order and after each one informed the test subject as to whether an adjacent or a separated pair of vertebrae was being tested.

\section{Results}

The number of correctly specified pairs was obtained for each test subject and the distribution of the observed outcomes is shown in Figure 1. Each of the 18 participants was confronted with 6 adjacent and 6 separate pairs in random order. If the null hypothesis is true (the participant cannot distinguish between adjacent and separated pairs of vertebrae), it could be expected that among 18 participants, 9 will have a value $X \leq 6$ and 9 will have a value $X \geq 7$. The real outcome was one participant with $X \leq 6$ and seventeen with $X$ $\geq 7$. The null hypothesis is therefore rejected $(\chi 2=14.28, P<$ $0.001^{* * *}, \mathrm{n}=18$, that is the number of statistically independent observations).

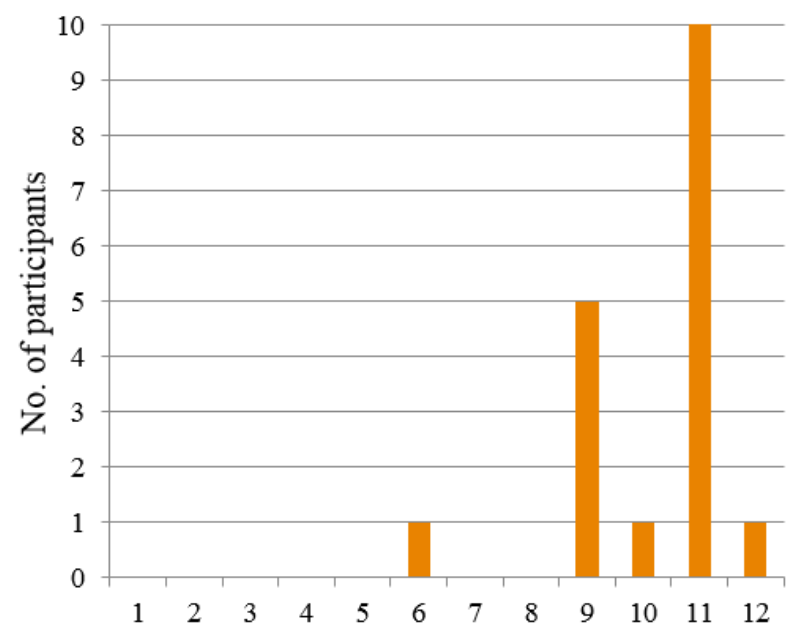

No. of correctly specified pairs $\left(\mathrm{X}_{\mathrm{a}}+\mathrm{X}_{\mathrm{s}}\right)$ $\mathrm{n}=18$. Seventeen participants with $\mathrm{X}>6$

Figure 1 Distribution of correctly specified pairs.

For each subject the proportion of correct classifications among the adjacent pairs is $\mathrm{Xa} / 6$.

For all, 18 volunteers there were altogether 87 correct classifications among the adjacent pairs, giving the mean $87 /(18 \times 6)=0.805$. This was regarded as the sensitivity for the method $[99 \% \mathrm{Cl}(0.69 ; 0.89)$ bootstrap]. In the same fashion the number of 96 correctly classified separate pairs gives a specificity of 0.89 [99\% Cl $(0.70 ; 0.95)$ bootstrap].

\section{Discussion}

The threshold for two-point-discrimination in the skin over the lumbar area has been found to be around 44-55 $\mathrm{mm}$ in healthy volunteers [1-3]. However, patients with painful conditions of the ankle, knee or wrist can often localize the deep pain origin rather well, why deep spatial discrimination might be as good as the cutaneous discrimination.

Our results in the present study, showing that healthy volunteers have a high capability (sensitivity 0.805) to discriminate between adjacent lumbar vertebrae lying only 2-3 $\mathrm{cm}$ apart, are promising with respect to the use of this test in 
clinical studies involving patients with presumed discogenic pain $[4,5]$.

Logically, provocative discography would be a suitable test for pinpointing a painful disc, but there is still much controversy in this regard [6-11]. In addition, disco-block has been described as a useful test [12], although it is not validated. Among the mechanical tests that are used, temporary external fixation has not been found to be reliable $[13,14]$, and the spinous process vibration test [15] is used infrequently and is not validated [4]. Currently, therefore, there is no reliable test to pinpoint a painful disc $[4,5]$ if one is present.

The next step would therefore be to study the deep spatial discrimination in patients presumed to have discogenic pain.

\section{Conclusion}

We found our test useful in discriminating deep structures of the spine lying only $2-3 \mathrm{~cm}$ apart. It might therefore be useful when searching for a possibly painful segment in patients with CLBP.

\section{Acknowledgement}

We are most grateful to all the volunteers who made this study possible.

\section{Funding}

The authors had no financial support.

\section{Disclosure of Interest}

The authors have no conflict of interest.

\section{References}

1. Catley MJ, Tabor A, Wand BM, Moseley GL (2013) Assessing tactile acuity in rheumatology and musculoskeletal medicine How reliable are two-point discrimination tests at the neck, hand, back and foot? Rheumatology 52: 1454-1461.

2. Moseley GL (2008) I can't find it! Distorted body image and tactile dysfunction in patients with chronic back pain. Pain 140 239-243.
3. Wand BM, Di Pietro F, George P, O'Connell NE (2010) Tactile thresholds are preserved yet complex sensory function is impaired over the lumbar spine of chronic non-specific low back pain patients: a preliminary investigation. Physiotherapy 96: 317-323.

4. Hancock MJ, Maher CG, Latimer J, Spindler MF, McAuley JH, et al. (2007) Systematic review of tests to identify the disc, SIJ or facet joint as the source of low back pain. Eur Spine J 16:1539-1550.

5. Willems PC, Staal JB, Walenkamp GHIM, De Bie RA (2013) Spinal fusion for chronic low back pain: systematic review on the accuracy of tests for patient selection. Spine J 13: 99-109.

6. Aprill C, Bogduk N (1992) High-intensity zone: A diagnostic sign of painful lumbar disc on magnetic resonance imaging. $\mathrm{Br} J$ Radiol 65: 361-369.

7. Bogduk N, Modic MT (1996) Controversy lumbar discography. Spine 21: 402-404.

8. Carragee EJ (2000) Is lumbar discography a determinate of discogenic low back pain: Provocative discography reconsidered. Curr Rev Pain 4: 301-308.

9. Madan S, Gundanna M, Harley JM, Boeree NR, Sampson M (2002) Does provocative discography screening of discogenic back pain improve surgical outcome? J Spinal Disord Tech 15: 245-251.

10. Simmons EH, Segil CM (1975) An evaluation of discography in the localization of symptomatic levels in discogenic disease of the spine. Clin Orthop Relat Res 108: 57-69.

11. Zdeblick TA (1999) Discogenic back pain. In: Rothman RH, Simeone FA (eds). The Spine. Philadelphia: WB Saunders pp. 749-765.

12. Ohtori $\mathrm{S}$, Kinoshita $\mathrm{T}$, Yamashita $\mathrm{M}$, Inoue $\mathrm{G}$, Yamauchi $\mathrm{K}$, et al. (2009) Results of surgery for discogenic low back pain. A randomized study using discography versus discoblock for diagnosis. Spine 34: 1345-1348.

13. Elmans L, Willems PC, Anderson PG, Van Limbeek J, De Kleuver $M$, et al. (2005) Temporary external transpedicular fixation of the lumbosacral spine. A prospective, longitudinal study in 330 patients. Spine 30: 2813-2816.

14. Willems P (2013) Decision making in surgical treatment of chronic low back pain. The performance of prognostic tests to select patients for lumbar spinal fusion. Acta Orthop 84 suppl 349: 1-35.

15. Yrjama M, Vanharanta $H$ (1994) Bony vibration stimulation: a new, non-invasive method for examining intradiscal pain. Eur Spine J 3: 233-235. 